\title{
Business architecture design for project management systems in the FMCG companies
}

\author{
Olga Voronova $^{1 *}$, Viktoria Sheleyko ${ }^{1}$, Igor Ilyin ${ }^{1}$, and Irina Ilyina ${ }^{2}$ \\ ${ }^{1}$ Peter the Great St. Petersburg Polytechnic University, Institute of Industrial Management, \\ Economics and Trade, 195251 Polytechnicheskaya, 29, Saint-Petersburg, Russia \\ ${ }^{2}$ Peter the Great St. Petersburg Polytechnic University, Institute of Humanities, 195251 \\ Polytechnicheskaya, 29, Saint-Petersburg, Russia
}

\begin{abstract}
The article considers the project management system as a tool for achieving strategic goals of network trading companies. This study is relevant, because in retail project management is widely used to solve unique and large-scale business problems, but the degree of prevalence of the project approach is still low, which affects the income of companies. In the course of the research, the classification of the activities of network trading companies, the functional-oriented organizational structure of project management of a network trading organization is presented, the model of the business architecture of project management of a network trading company is developed, and the algorithm of selection and the main functions of the software for project management are considered. As a result of the research, a standard project portfolio and a top-level model of the business architecture of a network trading company with an implemented corporate project management system were developed.
\end{abstract}

\section{Introduction}

Retail is one of those segments for which the implementation of project management is very important today. The network business may require the use of "project management", as a result of which the company will receive a reduction in the time or cost of completing these tasks. A successful trading company is constantly in the process of dynamic changes. A trade organization must be considered as a specific object that is constantly in the mode of constant transformations. In the field of trade, the activities of enterprises are always aimed at development. Modern commercial enterprises, in their aspirations to be successful and viable, are constantly searching for ways to improve their activities - one of the most successful ways to develop enterprises at present is organizational design. Most projects in retail are related to the automation of business, the opening of new points of sale, the opening or modernization of warehouses and distribution centres [1-5].

The use of modern project management methodology, according to research by the International Project Management Association (IPMA), can reduce the project time by 20$30 \%$ and its budget by $15-20 \%$. Given the scale of many networks and their multitasking, this is a real savings. Calculations show that on the horizon of 2-3 years, investments in

* Corresponding author: ilina.olga@list.ru 
technology not only pay off economically, but also allow you to stay afloat in a rapidly changing world. Retail has always been one of the most technologically advanced sectors of the Russian economy, second only to banks in terms of innovation. This is how it tries to remain today, despite the difficulties associated with the decline in the purchasing power of the population and the growth of competition in the market. These two factors lead to the fact that technology is becoming one of the most important tools for the survival and development of retail trade. In terms of infrastructure, large chain retailers have already implemented a digital transformation of the business and are now considering new niches for growth. They improve existing products and develop new areas that are considered promising. For example, retail is one of the first to introduce innovations that the entire market is talking about. These are artificial intelligence, the Internet of Things, machine learning, neural networks, and robotics

\section{Materials and methods}

This study used analytical methods such as description, data grouping, causal analysis, evaluation, and business architecture modelling methods. The modelling methods are implemented in the Archimate computer program, which allows you to quickly visualize objects and objects when entering data.The use of these methods allowed us to link disparate facts about the current situation of implementing a project management system in network trading companies in an environment where project management is used to solve unique and large-scale business tasks, but the degree of prevalence of the project approach is still low, which affects the income of companies.

\section{Results}

The first step towards digital transformation is the automation of the company's business processes, which should lead to a reduction in labour costs, obtaining operational and reliable analytics for making important management decisions, reducing accounts receivable and other effects. A comprehensive project management system is a tool for achieving business results, for implementing the strategy of network trading companies [68].

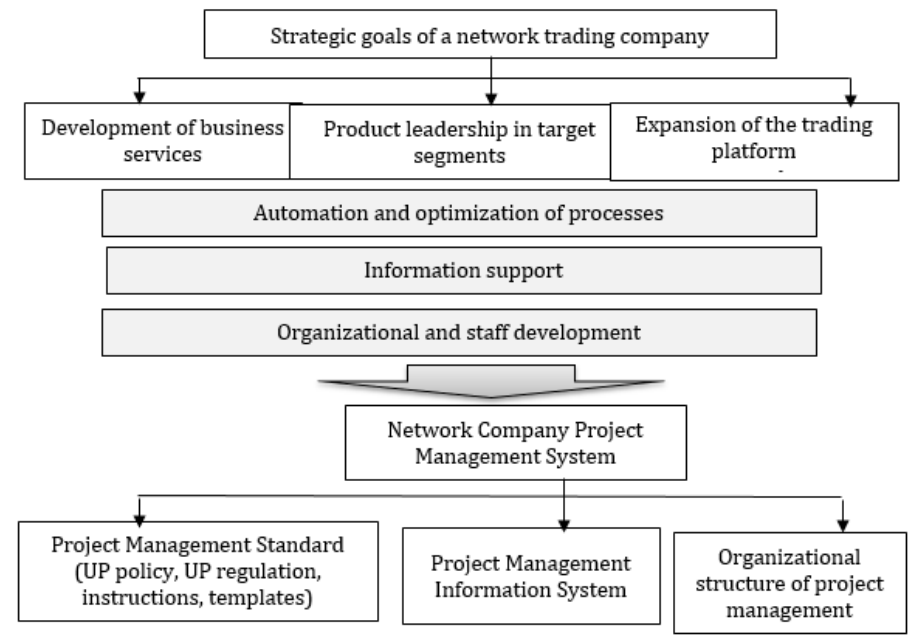

Fig. 1. Project management system of a network company as a tool for achieving a strategic goal. 
We will highlight the main tasks of implementing a corporate project management system:

- Increasing the share of successful projects.

- Implementation of only those projects that correspond to the strategy.

In this case, it is wrong to treat all actions as projects. You must correctly define the control objects. To do this, you need to classify all the company's activities into three groups, shown in Figure 2.

\begin{tabular}{|c|c|}
\hline & Classification of network trading company activities \\
\hline & Operational activities \\
\hline \multicolumn{2}{|c|}{$\begin{array}{l}\text { The activity of performing repetitive operations. } \\
\begin{aligned} \text { Operational business model of a network trading company: } \\
-\quad \text { interface for interacting with suppliers, } \\
-\quad \text { interface for interaction with consumers, } \\
-\quad \text { back office } \\
\text { Business processes of a network company: } \\
-\quad \text { managing business processes; } \\
-\quad \text { key business processes; } \\
-\quad \text { supporting business processes }\end{aligned}\end{array}$} \\
\hline \multicolumn{2}{|r|}{ Assignments } \\
\hline & $\begin{array}{l}\text { A one-time task with a specific performer and deadline, } \\
\text { tasks from the minutes of various meetings. }\end{array}$ \\
\hline \multicolumn{2}{|r|}{ Projects } \\
\hline & $\begin{array}{l}\text { Aunique (as opposed to operations) activity that has a beginning and an end in time, aimed at achieving a } \\
\text { certain unique result (goal, product, or service) under specified budget, resource, time, and content } \\
\text { constraints. }\end{array}$ \\
\hline
\end{tabular}

Fig. 2. Classification of network trading company activities.

In accordance with this classification, projects should not be considered as activities for performing repetitive operations and one-time tasks with specific performers and deadlines. Figure 3 shows the developed model of the project management business architecture of a network trading company [9]. 


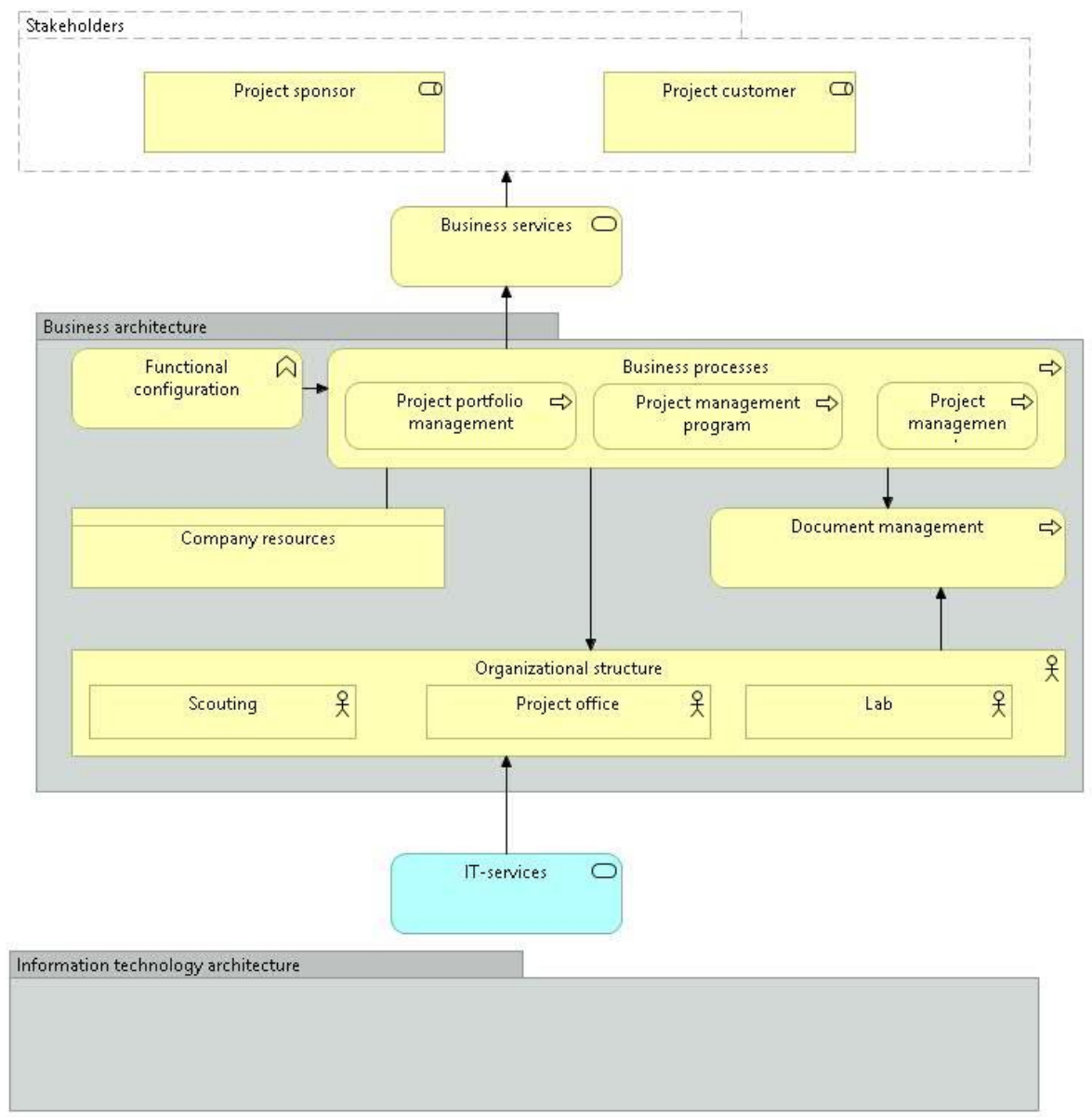

Fig. 3. Business architecture model for project management of a network trading company.

The basis of the business architecture of any enterprise is a system of business processes, which is formed on the basis of the functional structure of the business. The system of business processes determines the organizational structure, the system of document flow of the enterprise, the system of cash flows. Figure 4 shows the functional-oriented organizational structure of project management of a network trade organization [10-13]. 


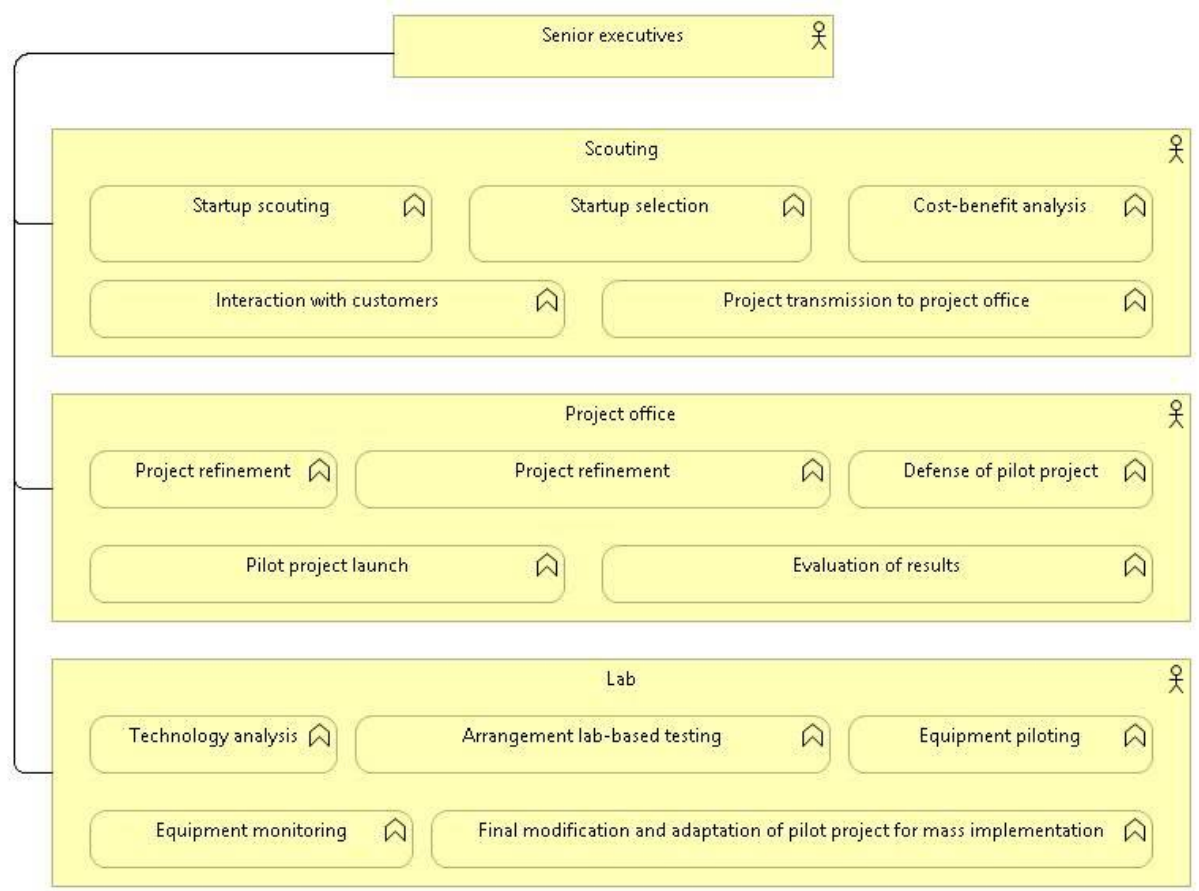

Fig. 4. Functional-oriented organizational structure of project management of a network trade organization.

In accordance with this structure, the following functions are assigned to the divisions:

Scouting-the search for specific technological solutions and projects, helps the customer company to reduce the time and cost of market research, to get a list of young companies interested in cooperation, with which you can test and create new products based on the current business.

- Project office - development of a pilot project from budget protection to rollout. As soon as the business client confirms their interest in the solution and their willingness to pilot it, the project office allocates a separate manager for the project.

- Laboratory-testing of innovative solutions on the basis of shop-laboratories, providing space for the installation of innovative equipment, assistance with testing, adaptation of the solution.

\section{Discussion}

As an example, consider the classification of project portfolios developed by the X5Lab team as part of the implementation of the priority direction of the X5 Retail Group development strategy, shown in the figure [14]. 


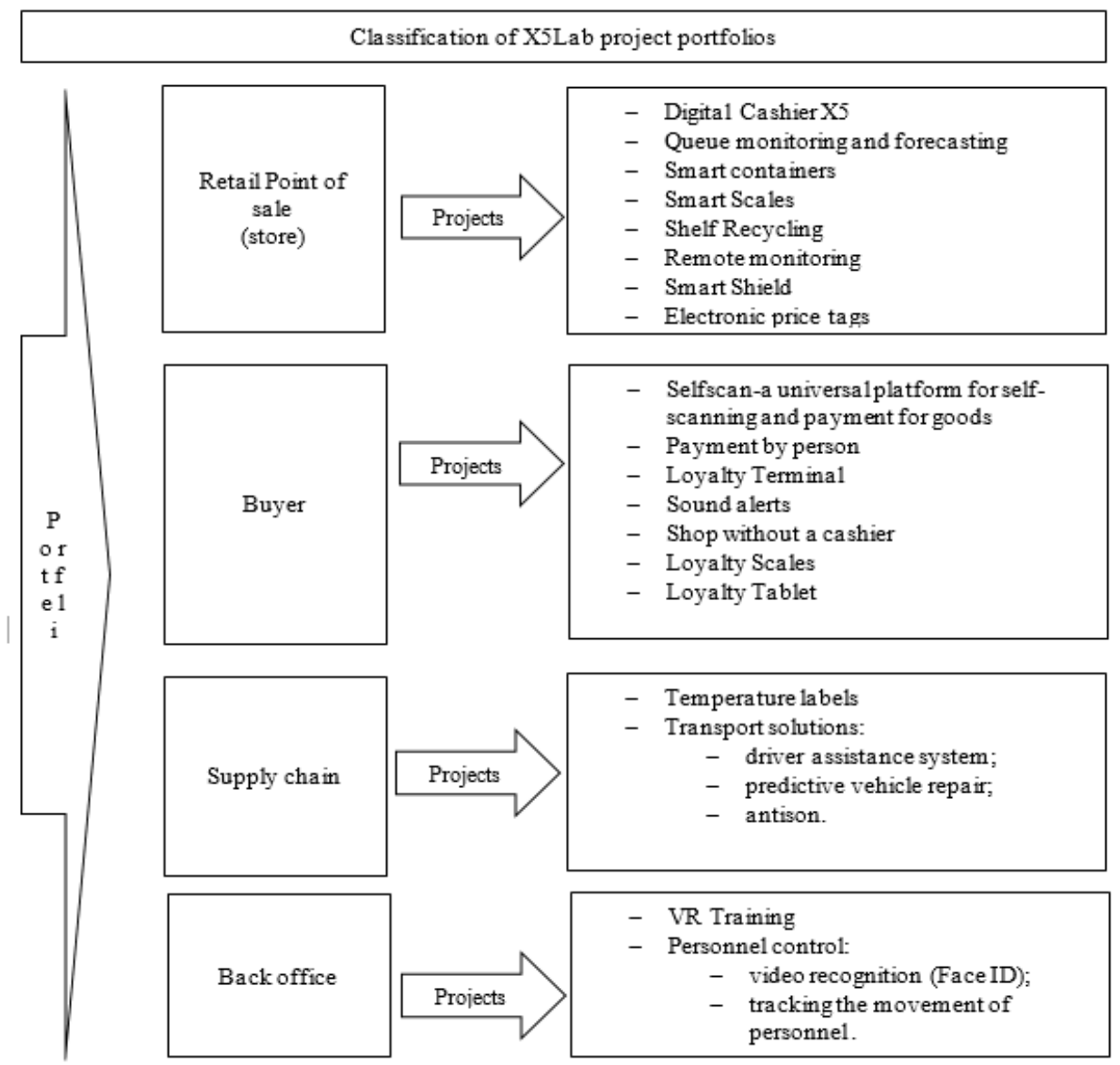

Fig. 5. Classification of $\mathrm{X} 5 \mathrm{Lab}$ project portfolios.

This company has implemented a significant number of projects to attract customers and interact with them more effectively. Many retail chains have made mobile applications, loyalty projects have appeared, and retailers have learned how to analyse customer behaviour and work with data.

In 2020, there was a fairly conscious demand for solutions for studying user experience, including video analytics. RPA, machine learning, and inventory management solutions were also popular.

In the central office of Metro, the first store without sellers, "Fasol", began testing. It uses electronic price tags, self-service cash registers, energy-saving refrigeration systems, and the app "Beans in the palm of your hand" allows you to remotely monitor key performance indicators.

A similar store "Pyaterochka" for employees was launched by X5 Retail Group. It uses the Internet of Things-with the help of sensors, the store's IT system automatically monitors the processes of entry, exit and movement of visitors, regulates the temperature regime, controls ventilation, lighting, detects smoke and ensures physical safety.

In several Magnit stores, it is now possible to pay for purchases using Face-ID — to do this, you need to register in the mobile app, enter your personal data and upload your photo. In addition, testing of the Pick-by-Voice voice control technology was completed at the Magnit warehouses. Now employees receive tasks, where and what goods to take, where to take them, not through a text message on the data collection terminal, but by voice, through 
headphones. Testing showed an 11 percent increase in labour productivity and is planned to be implemented in 38 distribution centres [15].

\section{Conclusions}

Software should be of great importance when implementing a corporate project management system. Project management software is designed to plan and control projects of any complexity and using a variety of methodologies, allowing you to perform management tasks using a range of planning tools, workload monitoring, performance monitoring, and resource allocation.

Project management programs, services and systems help teams and project managers manage team goals and long-term projects, as well as coordinate individual tasks, at the level of modern management methods. Such software products can be used in almost any industry that requires people to organize projects, tasks within projects, and goals for weekly, monthly, or annual projects.

Users use the software to track multiple projects, track the progress of a team or individual, and analyze team performance. Users usually have the ability to break down projects into individual tasks, create timelines (milestones) for project completion, analyze performance, and communicate with other team members.

Project management software is closely related to task management software, but differs in scale.

Project management software allows users to manage a team of individuals, balance projects, and document performance; task management software, most often, simply describes individual tasks, breaks down components within a project, sets deadlines, and allows self-management.

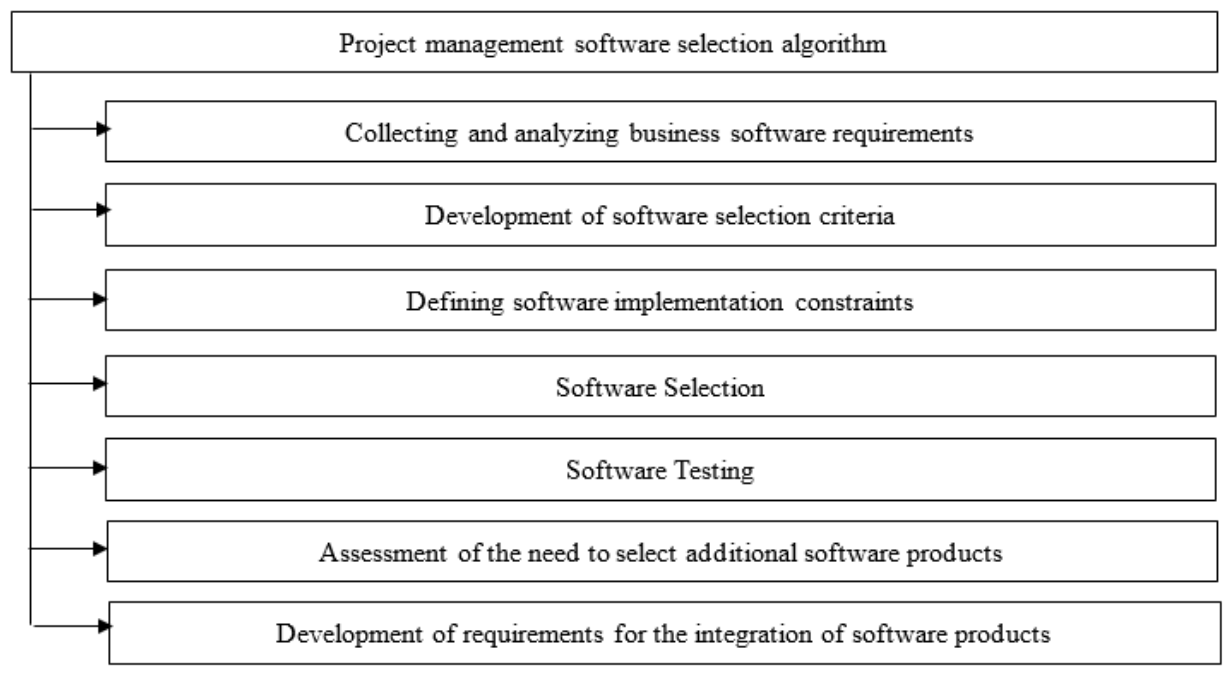

Fig. 6. Project management software selection algorithm

This company has implemented a significant number of projects to attract customers and interact with them more effectively. Many retail chains have made mobile applications, loyalty projects have appeared, and retailers have learned how to analyse customer behaviour and work with data.

In addition, for the optimal choice of project management software, it is necessary to clearly identify the main functions and capabilities of project management software in network trading companies. These include the functions shown in the figure. 
Key features and capabilities of project management software

Administration:

- the administration feature allows you to configure and manage system functionality, as well as manage accounts and access rights to the system;

- monitoring project progress, resource usage, and user performance;

- the ability to manage the interdependencies between tasks and their impact on deadlines.

Data Import / Export:

- the ability to import and/or export data in the product allows you to download data from the most popular file formats or upload working data to a file for further use in other software.

Multi-user access:

- the possibility of multi-user access to the software system provides simultaneous work of several users on the same database under their own accounts. Users in this case may have different access rights to the data and functions of the software.

Availability of the API:

- To meet the need for automatic data transfer from one software to another and similar interfaces, software systems are equipped with special Application Software Interfaces (eng. API, Application Programming Interface). For example, it is possible to automatically transfer data from the Customer Relationship Management System (CRM) to the Accounting System (BU). With the help of such APIs, any competent programmers will be able to link two software products to each other for automatic information exchange.

Reporting and analytics:

- ability to create project plans and programs, as well as work breakdown structures linked to project boundaries;

- ability to define, manage, and allocate resources based on need and availability;

- ability to create project budgets and compare them with actual costs and expenses;

- support for one or more project organization methodologies, such as (PMBOK, Agile, and others),

- the ability to use project templates that can be modified or combined to create new projects,

- provides project display in various views, such as calendar, client view, PERT, Gantt chart, and others.

Fig. 7. Key features and capabilities of project management software

It should be noted that the right choice of project management software allows you to get not only direct benefits, but also dramatically increase the accuracy of operational and managerial accounting, which will lead to more correct decisions and indirectly affect the increase in turnover and profit of network trading companies.

Based on the analysis of experience, we will select a typical portfolio of projects of a network trading company. 


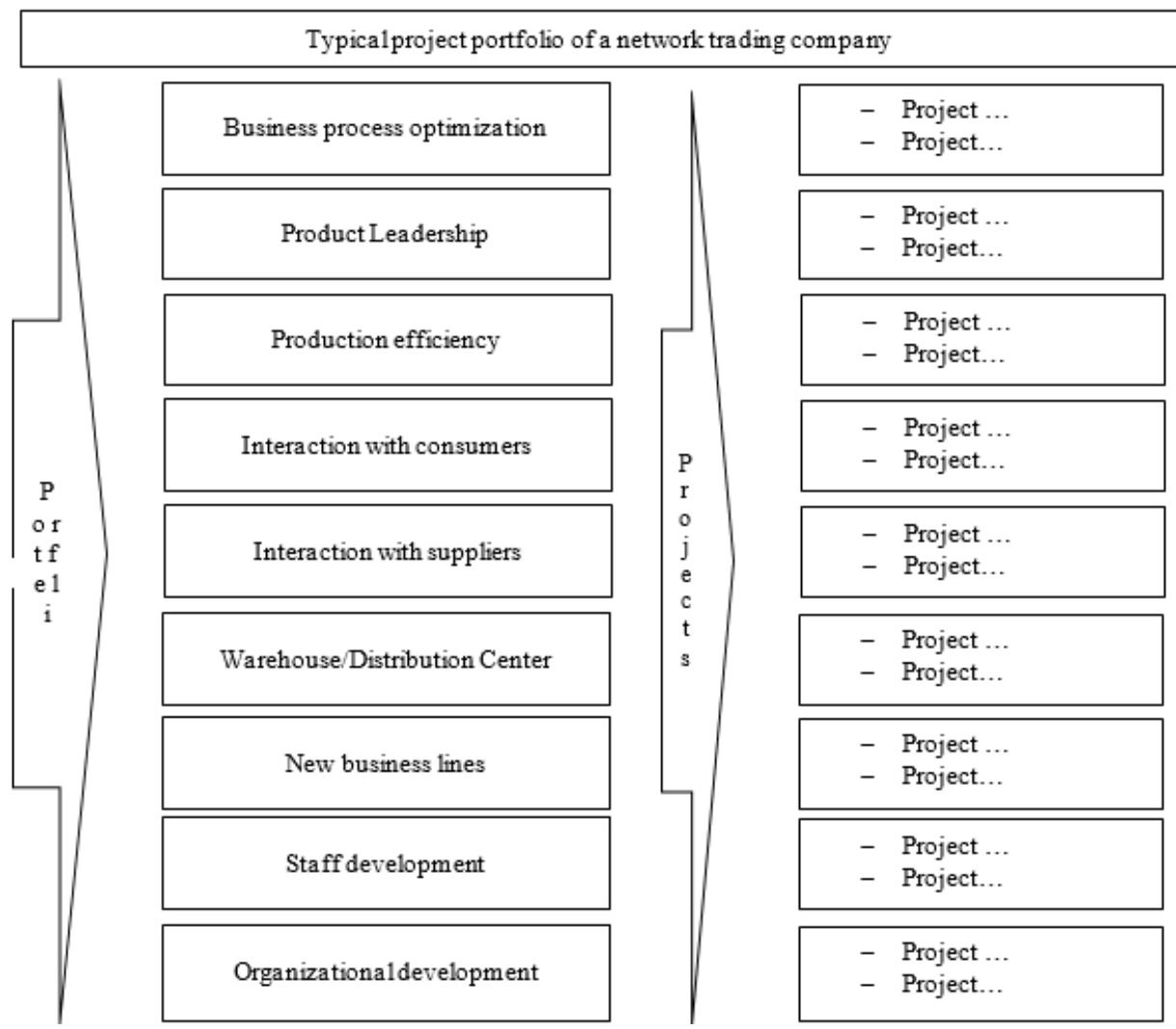

Fig. 8. Typical project portfolio of a network trading company

The figure shows the developed top-level model of the business architecture of a network trading company with an implemented corporate project management system.

Based on the analysis of experience, we will select a typical portfolio of projects of a network trading company. 


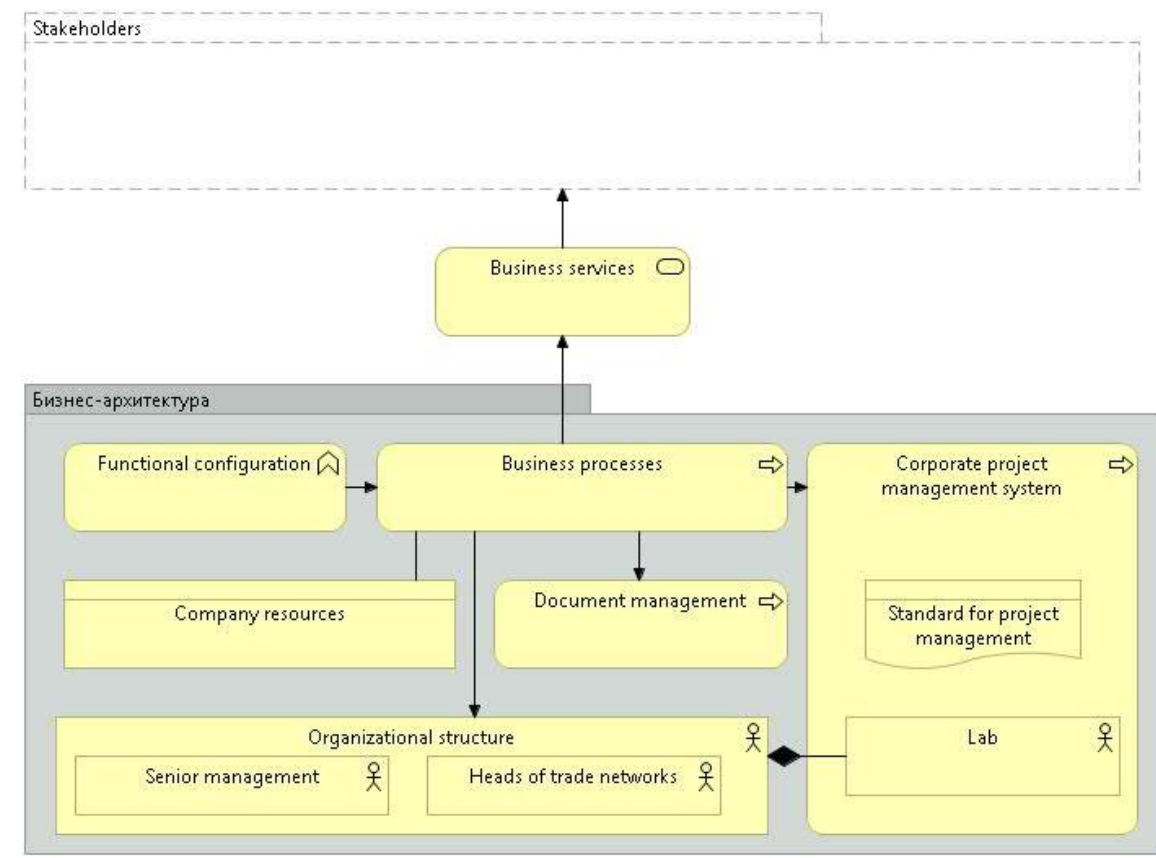

IT-services

IT-architecture

Fig. 9. Meta-model of the business architecture of a network trade organization

The project management system implemented in the business architecture of network trading companies will optimize the work of project managers and specialists, thanks to the following features:

- determination of the company's need for labour, financial and material resources;

- control over the execution of works, acceptance of services and use of materials;

- planning and active budget control, accounting for actual costs;

- building a work schedule and monitoring their execution;

- control of the procurement process;

- formation of analytical reports;

- full project lifecycle support.

Using a corporate project management system will help you automate the planning, management and control of long-term projects with a high level of complexity. For these purposes, the software allows you to maintain a hierarchical structure of projects, where work is divided into stages up to the level of individual operations, automatic analysis of material and resource requirements, cost accounting and budget control.

Today, in retail, project management is used to solve unique and large-scale business problems, but the degree of prevalence of the project approach is still low. Perhaps, the crisis will push retail to large-scale programs of changes in its business models and the 
need to implement new strategic tasks, and then the interest in project management in this area of business will increase.

\section{References}

1. S. Strite, H. Morkoc, J. Vac. Sci. Technol. 10 (1997)

2. A. Gusev, et al, J. Phys.: Conf. Series, 291 (2011)

3. M. Kurata, Numerical Analysis for Semiconductor Devices, 85 (1982)

4. K. Kunze, Phys. Rev. D, 68 (2003)

5. R. Caplar, P. Kulisic, Proc. Int. Conf. on Nuclear Physics, 1, 517 (1973)

6. T. Kuhn, Electronic Materials, 4, 173-214 (1986)

7. O. Voronova, I. Ilyin, Economics and Management J., 2, 78-85 (2018)

8. I. Ilyin, O. Voronova, Proc. of the 33rd International Business Information Management Association Conference, IBIMA, 5112-5121 (2020)

9. O. Voronova, E3S Web of Conferences, 09018 (2020)

10. A. Shubin, T.b. Business models of retail companies: how to compete with giants. Shubin, 276 (2016)

11. O. Voronova, Economics and Management J, 5, 81-88 (2019)

12. A. Smirnov, O. Ilina, Economics and Entrepreneurship J., 2, 523-527 (2017)

13. O. Ilina, Economics and Management J., 3, 88-93 (2007)

14. Retail portal, URL : https://www.retail.ru/articles/ - [Access mode 11.03.2021]

15. X-five retail, URL : http://x5lab.ru/- [Access mode 12.04.2021] 